\title{
Correspondence
}

\section{Severe hypercarbia with a Bain breathing circuit during malig- nant hyperthermia reaction}

To the Editor:

With better understanding of the rebreathing characteristics of T-piece systems in the last decade, ${ }^{1-5}$ these circuits have been found useful for controlled ventilation to obtain a desired arterial $\mathrm{PaCO}_{2}$ by means of controlled rebreathing. Arterial $\mathrm{PaCO}_{2}$ becomes fresh gas flow-dependent when the minute ventilation 10 fresh gas flow ratio exceeds 1.5 during controlled ventilation with $\mathrm{T}$-piece systems. ${ }^{5}$ Indeed, factors determining alveolar $\mathrm{CO}_{2}$ tension (and hence arterial $\mathrm{CO}_{2}$ tension) can be expressed by the following equation:

$$
\mathrm{FACO}_{2}=\mathrm{FICO}_{2}+\dot{\mathrm{VCO}_{2}} / \dot{\mathrm{V}}_{\mathrm{A}}
$$

where $\mathrm{FACO}_{2}$ is the alveolar carbon dioxide tension $\mathrm{FICO}_{2}$ is the inspired carbon dioxide tension; $\mathrm{VCO}_{2}$ is $\mathrm{CO}_{2}$ production in $\mathrm{ml} \cdot \mathrm{min}^{-1} ; \mathrm{VA}_{\mathrm{A}}$ is minute alveolar ventilation; $f=0.7$ (fractional utilization of fresh gas) when $\mathrm{VE} / \mathrm{FGF}>1.5$.

Recently in our institution, a malignant hyperthermia reaction in a patient ventilated with a Bain circuit, resulted in severe hypercarbia, due to the unrecognized increase in $\mathrm{CO}_{2}$ production $\left(\mathrm{VCO}_{2}\right)$, aggravated by rebreathing due to the breathing circuit.

The patient, a $45 \mathrm{~kg}$, 21-year-old female, was scheduled for elective left frontal parietal craniotomy for tumour. Past medical history included mild intermittent asthma and a seizure disorder related to her brain tumour. Previous anaesthetics for diagnostic laparoscopy and dilatation and curettage were unremarkable. Preoperative medications consisted of diphenylhydantoin and dexamethasone. No preopcrative scdation was given. Upon arrival in the operating room intravenous, intra-arterial and central venous pressure catheters were placed under local anaesthesia. After preoxygenation, induction of anaesthesia was carried out with fentanyl $100 \mu \mathrm{g}$, tubocurarine $2 \mathrm{mg}$, thiopentone $250 \mathrm{mg}$ and succinylcholine $100 \mathrm{mg}$ IV. The patient was intubated and anaesthesia was maintaincd with 60 per cent nitrous oxide/ 40 per cent oxygen, 1-1.5 per cent isoflurane, pancuronium and fentanyl.

An Ohio Modulus anaesthetic machine equipped with an Ohio 7000 ventilator was used. The patient was ventilated with a Bain circuit with a fresh gas flow of 4.5 $\mathrm{L} \cdot \mathrm{min}^{-1}$ and minute ventilation of $8.4 \mathrm{~L} \cdot \mathrm{min}^{-1}$. Proper Bain circuit function was verified by pressurizing the circuit and performing the Pethick test. ${ }^{6}$ The nitrous oxide and oxygen flow meters allowed maximum flows of 12 $\mathrm{L} \cdot \mathrm{min}^{-1}$ of each. Arterial blood gas analysis 45 minutes after induction revealed $\mathrm{pH} 7.35, \mathrm{PaCO}_{2} 38, \mathrm{PaO}_{2} 203$ $\left(\mathrm{PaCO}_{2}\right.$ was slightly elevated above predicted levels). Fresh gas flow was increased to $5 \mathrm{~L} \cdot \mathrm{min}^{-1}$ and minute ventilation to $11 \mathrm{~L} \cdot \mathrm{min}^{-1}$. In the next 45 minutes the patient had a persistent heart rate of $115 \mathrm{bpm}$ and a gradual rise in axillary temperature from 36 to $38^{\circ} \mathrm{C}$. During the subsequent 15 -minute interval a second anaesthetist's opinion was requested while other causes for the hyperthermia were discussed with the surgeon. The temperature was then noted to be $39^{\circ} \mathrm{C}$. Diagnosis of a probable malignant hyperthermia $(\mathrm{MH})$ reaction was made, because no other cause for the hyperthermia was evident. Blood gas analysis at this time revealed $\mathrm{pH} 6.91, \mathrm{PaCO}_{2}$ $121, \mathrm{PaO}_{2} 72$. Our therapy for the suspected $\mathrm{MH}$ reaction included topical cooling, dantrolene $100 \mathrm{mg}$ IV, sodium bicarbonate $100 \mathrm{mg}$ intravenously and attempted hyperventilation with a fresh gas flow of $12 \mathrm{~L} \cdot \mathrm{min}^{-1}$ of oxygen (maximum for this machine) with minute ventilation of 18 $L \cdot \min ^{-1}$ using the existing Bain circuit.

A calibrated capnograph was then added to the system and an end-tidal $\mathrm{PCO}_{2}$ of $75 \mathrm{mmHg}$ was measured from the proximal end of the endotracheal tube. Inspiratory $\mathrm{PCO}_{2}$ was elevated but the number not recorded. After substitution with a circle system with fresh soda lime, the end-tidal $\mathrm{PCO}_{2}$ immediately fell to $35 \mathrm{mmHg}$ at a minute ventilation of $15 \mathrm{~L} \cdot \mathrm{min}^{-1}$ and fresh gas flow of 10 $L \cdot \min ^{-1}$ oxygen. The Bain circuit was not visibly damaged but was not retested. The patient's temperature peaked at $39.8^{\circ} \mathrm{C}$ but fell rapidly to $37.3^{\circ} \mathrm{C}$ over 45 minutes. Nasal and rectal temperature probes confirmed the hyperthermia and were used to follow the course of the suspected MH reaction. Postoperative recovery was subsequently uncomplicated and serum CPK levels revealed a moderate rise only.

We feel this case emphasizes several points. In usual circumstances normocapnia can be achieved with use of a T-piece system by controlled rebreathing. ${ }^{5}$ However, hypercarbia may result when $\mathrm{VCO}_{2}$ is markedly increased.

According to the above formula, $\mathrm{FACO}_{2}$ increases as a result of both increased $\mathrm{VCO}_{2}$ and $\mathrm{FiCO}_{2}$ in a T-piece 
system. In a non-rebreathing system $\mathrm{VCO}_{2}$ is the only variable affected and the hypercapnia which occurs is not aggravated by rebreathing.

Secondly, the use of a Bain citcuit during a hypermetabolic state such as an $\mathrm{MH}$ reaction is limited by the maximum oxygen flow rate available from the anaesthetic machine. Even with a frcsh gas flow of $12 \mathrm{~L} \cdot \mathrm{min}^{-1}$ we did not achieve normocapnia as we discovered when we inserted the capnograph into our circuit. Of interest, prior to modifying this machine, the oxygen flowmeter allowed a flow of only $6 \mathrm{~L} \cdot \mathrm{min}^{-1}$.

Finally, we feel that protocols for anaesthetic management of malignant hyperthermia should emphasize the problem of excessive $\mathrm{CO}_{2}$ production during an $\mathrm{MH}$ reaction and gas-free machines should avoid $\mathrm{T}$-piece circuits. The present protocol of the Anaesthesia Section of the Ontario Medical Association? suggests "all new tubing, plus fresh soda lime where being used." We feel that a circle system plus fresh soda lime should be recommended as the circuit of choice and that a $T$-piece system (such as a Bain circuit) or a circuit incorporating only a non-rebreathing valve should not be used unless very high flows of oxygen can be provided.

\section{Kent H. Rogers MD FRCPC}

D. Keith Rose MD FRCPC

Robert J. Byrick MD FRCPC

Department of Anaesthesia,

St. Michael's Hospital, 30 Bond Street,

Toronto, Ontario,

MSB IW8

\section{REFERENCES}

1 Bain JA, Spoerel WE. Flow requirements for a modified Mapleson $D$ system during controlled ventilation. Can Anaesth Soc J 1973; 20: 629-36.

2 Bain JA, Spoerel WE. Carbon dioxide output and climination in children under anaesthesia. Can Anaesth Soc J 1977; 24: 533-9

3 Seeley $H F$, Barnes $P K$, Conway CM. Controlled ventilation with the Mapleson D system. Br J Anaesth 1977; 49: $107-14$.

4 Rayburn RL, Graves $S A$. A new concept in controlled ventilation of children with Bain anesthetic circuit. Anesthesiology 1978; 48: 250-95.

5 Rose $D K$, Froese $A B$. The regulation of $\mathrm{PaCO}_{2}$ during controlled ventilation of children with a T-piece. Can Anaesth Soc J 1979; 26: 104-13.

6 Pethick SL. Letter to the Editor. Can Araesth Soc J 1975; 22: 115 ,

7 Malignant Hyperthermia Protocol, Section on Anaesthesia, Ontario Medical Association, 250 Bloor Strcet East, Suite 600, Toronto, Ontario M4W 3P8, July 1985.

\section{Increased resistance to breath- ing: potentially lethal hazard across a coaxial circuit- connector coupling}

To the Editor:

We wish to acknowledge Drs. Branson and Lam's' recent findings related to the use of "high shoulder" ET tube connectors and the CPRAM ${ }^{\mathrm{TM}}$ coaxial breathing circuit.

The design of the CPRAM ${ }^{\mathrm{TM}}$ circuit was intended to forego the use of this type of connector, also known as "low dead space," with its extended tip design. It has been recognized that these connectors in combination with any fresh gas adapter which has an extended tip design, could cause increased resistance to breathing.

In a US Food and Drug Administrated Safety Atert, dated September 2, 1983, this potential hazard was addressed. ${ }^{2}$ A mailing to various hospital departments as well as publication in several journals was done.

In support of this, we have always included a "Warning" in our product labelling regarding this matter. This warning reads as follows: Do not wse with endotracheal tube, tracheostomy tube or airway connectorsiadapters (including gas sampling) which have small internal orifices or "low dead space." Occlusion of the fresh gas flow may result.

As the sole manufacturer of the CPRAM ${ }^{\mathrm{TM}}$ circuit, we feel a strong obligation to the clinician to inform them of any potential hazard.

We again, appreciate the concern of Drs. Branson and Lam.

Paul E. Dryden

President

Dryden Corporation

10640 East 59 th Strect

PO Box 36038

Indianapolis, Indiana 46236

U.S.A.

\section{REFERENCES}

I Branson $R$, Lam $A M$. Increased resistance to breathing: a potentially lethal hazard across a coaxial circuitconnector coupling. Can Anaesth Soc J. 1987; 34: S90-S91.

2 US Food and Drug Administration, FDA Safety Alert: Breathing System Connectors, September 2, 1983. 